\title{
URINARY DYSFUNCTION AFTER SURGICAL TREATMENT FOR RECTAL CANCER
}

\author{
Fernando Bray BERALD01, Sonia Ahlaim Ibrahim YUSUF ${ }^{1}$, Rogério Tadeu PALMA, \\ Silvia KHARMANDAYAN ${ }^{2}$, José Eduardo GONÇALVES ${ }^{1}$ and Jaques WAISBERG ${ }^{1,2}$
}

\begin{abstract}
Background - The impact on quality of life attributed to treatment for rectal cancer remains high. Deterioration of the urinary function is a relevant complication within that context. Objective - To detect the presence of urinary dysfunction and its risk factors among individuals underwent surgical treatment for rectal cancer. Methods - The present prospective study analyzed 42 patients from both genders underwent surgical treatment for rectal adenocarcinoma with curative intent. The version of the International Prostatic Symptom Score (IPSS) questionnaire validated for the Portuguese language was applied at two time-points: immediately before and 6 months after surgery. Risk factors for urinary dysfunction were analysed by means of logistic regression and Student's $t$-test. Results - Eight (19\%) participants exhibited moderate-to-severe urinary dysfunction 6 months after surgery; the average IPSS increased from 1.43 at baseline to 4.62 six months after surgery $(P<0.001)$. None of the variables assessed as potential risk factors exhibited statistical significance, i.e., age, gender, distance from tumour to anal margin, neoadjuvant therapy, adjuvant therapy, type of surgery, surgical approach (laparoscopy or laparotomy), and duration of surgery. Conclusion - This study identified an incidence of $19 \%$ of moderate to severe urinary dysfuction after 6 months surveillance. No risk factor for urinary dysfunction was identified in this population.
\end{abstract}

HEADINGS - Rectal neoplasms. Neurogenic urinary bladder. Colorectal surgery. Neoadjuvant therapy. Hypogastric plexus.

\section{INTRODUCTION}

Surgical treatment is the basis of curative rectal cancer treatment ${ }^{(8,9,10,18)}$. The concept of total mesorectal excision (TME), which includes anatomical dissection of the pelvic fascia and recognition of vascular and nerve structures, has allowed better outcomes in terms of local recurrence and functional morbidity of the pelvic organs ${ }^{(11,12,15)}$.

The function of the pelvic organs depends on the neural integrity of the pelvic autonomic plexuses; thus, its preservation is one of the priorities in surgery ${ }^{(6,27)}$. The voluntary control of the lower urinary tract depends on the adequate interaction of the autonomic innervation, mediated by sympathetic and parasympathetic fibres, with the somatic innervation, mediated by the pudendal nerves ${ }^{(7,19)}$.

Although results relative to oncological radicality have exhibited significant improvement, the impact on quality of life in rectal cancer treatment can also be affected by the presence of urinary disfunction which might be as high as 30\% ${ }^{(16,30)}$.

Dysfunction of the lower urinary tract is associ- ated with neural injury during surgery, which might occur even when TME is properly performed ${ }^{(27,30)}$. Lesions of the pelvic autonomic nerve plexus might occur either alone or in association with other lesions and are due to tumour infiltration, difficult dissection of large tumours, or inadequate dissection of the anatomic planes ${ }^{(27)}$.

The aim of this study was to detect the presence of urinary dysfunction and to identify the risk factors for its occurrence among patients with rectal cancer that underwent surgery with curative intent.

\section{METHODS}

This prospective study was conducted with patients with rectal cancer underwent to curative surgery from January 2011 to January 2012. Forty-nine adults from both genders with rectal cancer TNM stages I, II or III were initially included ${ }^{(24)}$. Subjects with distant metastasis, with moderate or severe urinary dysfunction, and urgency surgery were excluded from the study.

The preoperative tumour staging was based on the results of colonoscopy, rigid proctosigmoidoscopy,

Declared conflict of interest of all authors: none.

Financial support: This study had financial support of master's degree scholarship by Coordenação de Aperfeiçoamento de Pessoal de Nivel Superior (CAPES).

Serviço de Gastroenterologia Cirúrgica, Hospital do Servidor Público Estadual de São Paulo, São Paulo, SP; ${ }^{2}$ Departamento de Cirurgia, Faculdade de Medicina do ABC, Santo André, SP. Brasil.

Correspondence: Fernando Bray Beraldo. Rua Pedro de Toledo, 1800, 11ªndar. Ala central. São Paulo, SP, Brasil. Email: gastroprocto_sp@outlook.com 
carcinoembryonic antigen (CEA) plasma levels, magnetic resonance imaging of the pelvis and helical computed tomography of the abdomen and chest.

The presence of stage II or III extraperitoneal rectal carcinoma was the criterion selected for indication of neoadjuvant therapy. The patients underwent surgery 6 to 8 weeks after the end of neoadjuvant treatment, which included radiation therapy in a total dose of 5,040 cGy distributed over 5 weeks and chemotherapy with 5 -fluorouracil $\left(425 \mathrm{mg} / \mathrm{m}^{2}\right)$ and folinic acid $\left(20 \mathrm{mg} / \mathrm{m}^{2}\right)$ on the first three days of the first and last weeks of radiotherapy.

Adjuvant treatment was indicated to patients with high-risk stage II (baseline CEA $>10 \mathrm{ng} / \mathrm{mL}$, aneuploidy, angiolymphatic invasion or perineural invasion) or stage III tumours. The chemotherapy used for adjuvant therapy were applied for 6 months. The regimen for stage II tumours included capecitabine $2,000 \mathrm{mg} / \mathrm{m}^{2}$ in two daily doses from D1 to D14, repeating the cycle every 3 weeks for eight cycles, or folinic acid $500 \mathrm{mg} / \mathrm{m}^{2}$, followed by 5 -fluorouracil $500 \mathrm{mg} / \mathrm{m}^{2}$, once per week for 6 weeks, repeating the cycle every 8 weeks for three cycles. The regimen for stage III tumours included capecitabine $2000 \mathrm{mg} / \mathrm{m}^{2}$ in two daily doses for 14 days, combined with oxaliplatin $130 \mathrm{mg} / \mathrm{m}^{2}$ on D1, repeating the cycle every 3 weeks for eight cycles, or oxaliplatin $85 \mathrm{mg} / \mathrm{m}^{2}$ and folinic acid $200 \mathrm{mg} / \mathrm{m}^{2}$ on D1 combined with 5 -fluorouracil $400 \mathrm{mg} / \mathrm{m}^{2}$ in intravenous bolus followed by $1,200 \mathrm{mg} / \mathrm{m}^{2}$ in continuous infusion for 22 hours every 2 weeks for 12 cycles.

The patients were assessed at the time when preoperative staging was performed and 6 months after surgery using the version of the International Prostatic Symptom Score (IPSS) questionnaire validated for the Portuguese language ${ }^{(2,3)}$. The IPSS consists of seven questions to assess the occurrence of the following urinary symptoms in the previous 4 weeks: incomplete emptying of the bladder, frequency, intermittency, urgency, weak stream, straining and nocturia. The total score was calculated by adding the score assigned to each individual question. Scores are assigned based on the intensity of symptoms on a scale ranging from zero (absent) to five (strong) (Figure 1), and the total score varies from zero to 35 . The severity of urinary dysfunction was categorised based on the total score as follows: mild (one to seven points), moderate (eight to 19 points) and severe (20 to 35 points).

To assess the correlation of risk factors for urinary dysfunction, the participants were divided into two groups: subjects with no worsening of the urinary symptoms 6 months after surgery, i.e., those who showed the same scores at baseline and reassessment, and patients who showed an increase in the IPSS at reassessment compared to baseline.

The variables selected as potential risk factors were median age $<$ or $\geq 63$ years old; gender; distance from the tumour lower margin to the anal margin $\leq 9 \mathrm{~cm}$ or $>9 \mathrm{~cm}$; performance or not of neoadjuvant and/or adjuvant therapy; type of surgery; surgical approach (laparoscopy or laparotomy); and duration of surgery. The surgical procedures were categorised as rectosigmoid resections (low anterior rectosigmoid resection, high anterior rectosigmoid resection, anterior rectosigmoid resection with proximal colostomy + burying of the distal stump) or abdominoperineal resection. The average surgical duration was categorised as $\leq$ or $>4$ hours.

Descriptive analysis included calculation of the arithmetic mean, standard deviation and median, relative frequency expressed as percentage, minimum and maximum values, a logistic regression model and Student's $t$-test. The significance level was set at $5 \%(P \leq 0.05)$. Analysis was performed using the SPSS V17 software (SPSS Inc., Chicago, IL, USA).

\begin{tabular}{|l|c|c|c|c|c|c|}
\hline \multicolumn{7}{|c|}{ International Prostatic Symptom Score } \\
\hline & $\begin{array}{c}\text { Not at } \\
\text { all }\end{array}$ & $\begin{array}{c}\text { Less than } \\
1 \text { in } 5 \\
\text { times }\end{array}$ & $\begin{array}{c}\text { Less than } \\
\text { half the } \\
\text { times }\end{array}$ & $\begin{array}{c}\text { About } \\
\text { half the } \\
\text { times }\end{array}$ & $\begin{array}{c}\text { More } \\
\text { than half } \\
\text { the times }\end{array}$ & $\begin{array}{c}\text { Almost } \\
\text { always }\end{array}$ \\
\hline $\begin{array}{l}\text { How often have you had the sensation of not emptying } \\
\text { your bladder? }\end{array}$ & 0 & 1 & 2 & 3 & 4 & 5 \\
\hline $\begin{array}{l}\text { How often have you had to urinate less than every two } \\
\text { hours? }\end{array}$ & 0 & 1 & 2 & 3 & 4 & 5 \\
\hline $\begin{array}{l}\text { How often have you found you stopped and started again } \\
\text { several times when you urinated? }\end{array}$ & 0 & 1 & 2 & 3 & 4 & 5 \\
\hline $\begin{array}{l}\text { How often have you found it difficult to postpone } \\
\text { urination? }\end{array}$ & 0 & 1 & 2 & 3 & 4 & 5 \\
\hline How often have you had a weak urinary stream? & 0 & 1 & 2 & 3 & 4 & 5 \\
\hline How often have you had to strain to start urination? & 0 & 1 & 2 & 3 & 4 & 5 \\
\hline & None & 1 time & 2 times & 3 times & 4 times & 5 times \\
\hline $\begin{array}{l}\text { How many times did you typically get up at night to } \\
\text { urinate? }\end{array}$ & 0 & 1 & 2 & 3 & 4 & 5 \\
\hline
\end{tabular}

FIGURE 1. Version of the International Prostatic Symptom Score (IPSS). 


\section{RESULTS}

Clinical staging was performed in 49 subjects. Application of the IPSS revealed that $7(14 \%)$ patients who had moderate-to-severe urinary dysfunction (score $\geq 8$ ) were excluded from the study. Thus, the final sample consisted of 42 subjects.

Twenty-six $(61.9 \%)$ were female and $16(38.1 \%)$ male; the average age of the sample was $61 \pm 12.2$ years old (range, 36 to 86 years old).

The distances from the tumour's lower margin to the anal margin were $\leq 9 \mathrm{~cm}$ in $28(66.6 \%)$ cases and $>9 \mathrm{~cm}$ in 14 $(33.3 \%)$. Twenty $(47.6 \%)$ subjects were undergone to neoadjuvant therapy and $24(57.1 \%)$ to adjuvant therapy.

Rectosigmoid resection was performed in $31(73.8 \%)$ cases and abdominoperineal resection in $11(26.1 \%)$. Laparoscopy was performed in $24(57.1 \%)$ cases and laparotomy in 18 $(42.9 \%)$. Conversion of laparoscopic to open surgery occurred in one $(4.1 \%)$ case following identification of tumour infiltration of the bladder and uterus. The average surgical duration was $4.1 \pm 0.6$ hours ( 3.5 to 7 hours). The average duration of laparoscopic surgery was 4.2 hours, and that of laparotomy surgery was 4 hours.

Five $(16.6 \%)$ patients developed anastomotic fistula; all of them underwent neoadjuvant therapy, and only one the surgical approach wasn't laparoscopic. All these cases progressed with no further complications, and none required additional surgery or percutaneous drainage.

All surgeries had curative intent, and the surgical margins were negative on microscopic analysis in all of them. Postoperative clinical staging indicated seven $(16.6 \%)$ stage I tumours, $11(26.1 \%)$ stage II tumours and $22(52.3 \%)$ stage III tumours. Two $(4.7 \%)$ subjects exhibited pathologic complete response to neoadjuvant therapy (stage 0 ).

One $(2.3 \%)$ participant required indwelling catheterisation in the postoperative period due to urinary retention.

Six months after surgery, the IPSS had not increased in $22(52.3 \%)$ participants. Mild urinary dysfunction (score $\leq 7$ ) was detected in $12(28.5 \%)$ participants, moderate dysfunction (score $\geq 8$ to $<20)$ in $7(16.6 \%)$ and severe dysfunction (score $>20)$ in $1(2.3 \%)$ (Table 1). The average result on the IPSS increased from 1.43 before surgery to 4.62 six months later $(P<0.001)$.

TABLE 1. Incidence of urinary dysfunction as assessed by the IPSS 6 months after surgical treatment for rectal carcinoma

\begin{tabular}{lc}
\hline Classification - IPSS & N \% \\
\hline Participants with no aggravation of urinary symptoms & $22(52.3 \%)$ \\
Mild urinary dysfunction & $12(28.5 \%)$ \\
Moderate-to-severe urinary dysfunction & $8(19.0 \%)$ \\
Total & $42(100 \%)$
\end{tabular}

N: number of patients; IPSS: International Prostatic Symptom Score.
In regard to the specific urinary symptoms, the irritative symptoms prevailed over the obstructive ones (Table 2). All $20(47.6 \%)$ patients who mentioned urinary symptoms reported nocturia, and 15 of them $(75.0 \%$ of the group with worse scores) reported increased urinary frequency.

TABLE 2. Urinary symptoms 6 months after surgical treatment of rectal carcinoma

\begin{tabular}{lc}
\hline Urinary symptoms & $\mathbf{N} \%$ \\
\hline Nocturia & $100 \%(20 / 20)$ \\
Urinary frequency & $75.0 \%(15 / 20)$ \\
Urinary urgency & $50.0 \%(10 / 20)$ \\
Incomplete bladder emptying & $45.0 \%(9 / 20)$ \\
Weak stream & $45.0 \%(9 / 20)$ \\
Intermittency & $45.0 \%(9 / 20)$ \\
Hesitancy/strain & $40.0 \%(8 / 20)$ \\
\hline
\end{tabular}

$\mathrm{N}$ : number of patients.

There was no statistical significance of the variables selected as potential risk factors for deterioration of the urinary function in the logistic regression model. The variables gender $(P=0.109$; coefficient $=-2.372)$, age $(P=0.117$; coefficient $=0.134)$, distance from the tumour's lower margin to the anal margin $(P=0.284$; coefficient $=-0.586)$, use of adjuvant therapy $(P=0.636$; coefficient $=0.770)$, use of neoadjuvant therapy $(P=0.966$; coefficient $=0.075)$, surgery type $(P=0.779$; coefficient $=1.161)$ surgical approach $(P=0.568$; coefficient $=1.127)$ and duration of surgery $(P=0.092$; coefficient $=2.505$ ) were no statistic significance.

\section{DISCUSSION}

A wide scope of well-established surgical techniques and approaches for the treatment of rectal cancer is currently available, in addition to advances in radiotherapy and chemotherapy ${ }^{(8)}$. However, the functional sequelae of those treatments in the pelvis are still a topic of discussion, considering that no conclusive results have been reported as to the main risk factors associated with such sequelae or on the best strategies to prevent them. Urinary dysfunction is a relevant topic due to its prevalence and impact on patients' quality of life ${ }^{(8,26)}$. Some authors reported increasingly better functional postoperative outcomes, especially after adequate mesorectal excision, as proposed by Heald et al. became routine, combined with a rational use of radiotherapy and chemotherapy ${ }^{(12,14,18)}$.

Rectal cancer poses two significant problems from the therapeutic standpoint: local recurrence and injury of the autonomic innervation of the pelvis. Efforts were devoted to reducing the rate of local recurrence through improvement of the surgical technique, performance of TME and development and improvement of neoadjuvant therapy. However, surgeons have direct attention to the preservation of the pelvic nerves in the surgical treatment of rectal cancer. Some authors have investigated the mechanisms of neural 
injury aiming to promote the preservation of the autonomic innervation of the pelvis and to thus reduce the incidence of functional sequelae ${ }^{(6,7,19,22,26,32)}$. Such mechanisms include the injury of either the inferior hypogastric plexus or the pelvic splanchnic nerves due to violation of the avascular plane between the visceral and parietal pelvic fascia ${ }^{(22,27)}$. Ligation of the inferior mesenteric artery at its origin, close to the aorta, with sectioning of superior hypogastric plexus fibres concomitant or not to sectioning of the inferior hypogastric plexus is another neural injury mechanism that has been investigated ${ }^{(6,7,19,22,27,32)}$. Studies based on cadaveric surgery showed that dissection along the presacral fascia and injury of the levator ani nerve, which innervates the levator ani muscle, a crucial component of the urinary and faecal continence system, are also causes of sequelae affecting the pelvic floor ${ }^{(32)}$.

The psychometric index IPSS, which was formulated by the American Urologic Association in 1992 to assess benign prostatic hyperplasia, was selected for use in the present study based on the need for a short, practical, clinically sensitive and self-report questionnaire able to capture the severity of obstructive and/or irritative urinary symptoms ${ }^{(2,3)}$. IPSS is a self-report instrument, thus, the bias associated with the examiner's subjectivity is avoided. In addition, as respondents should assess their condition according to the previous month, the reliability of the information is ensured, as the bias associated with day-to-day variability is avoided.

Seven (14\%) pacients reported moderate-to-severe urinary symptoms before surgical treatment, only one of them was female. Thus, those symptoms were attributed to probable benign prostate disease. This finding is relevant because it points to the necessity to functional assessment of the pelvic organs before surgery to provide them more accurate information for development or worsening of urinary dysfunction following surgery for rectal cancer. Hendren et al. ${ }^{(13)}$ found that only $9 \%$ of women and $39 \%$ of men in their study remembered having discussed the potential complications of surgical treatment for rectal cancer with the medical staff.

The results of the postoperative assessment of the urinary function in this study were similar to those reported in other studies $^{(16,20)}$ that also used the IPSS.

Among urinary symptoms the irritative: nocturia and increased urinary frequency were the most common, $100 \%$ and $75 \%$, respectively. Those symptoms are usually associated with mild pelvic neural injury compared to the obstructive symptoms ${ }^{(6,27)}$. Similar findings were described by Sartori et al. ${ }^{(30)}$ and Breukink et al. ${ }^{(4)}$, who reported nocturia and increased urinary frequency, respectively, as the most prevalent symptoms. In the present study, one of the patients exhibited severe obstructive symptoms of urinary retention after surgery and required indwelling catheterisation. The urodynamic tests indicated a case of neurogenic bladder. At the 6-month assessment, the patient exhibited partial improvement following the use of oxybutynin chlorhydrate and no longer required the use of either an indwelling or intermittent urinary catheter. That patient underwent neo- adjuvant therapy followed by abdominoperineal resection via laparotomy, while tumour infiltration of the rectoprostatic (Denonvilliers') fascia and prostatic capsule was noted during surgery, which might account for the progression he exhibited.

In the present study, neoadjuvant therapy did not behave as a risk factor for worsening of the urinary symptoms. This finding disagrees with the results of the studies by Pollack et al. ${ }^{(28)}$ and Bruheim et al. ${ }^{(5)}$. Eveno et al. ${ }^{(6)}$ described the actinic effect on the pelvic vessels and nerves to account for the potential damaging effect on the urinary function, similar to the treatment of prostate cancer. The damage caused by radiotherapy to the pelvic organs was greater when it was applied after surgery ${ }^{(31)}$.

In the present study, neither rectosigmoid resection nor abdominoperineal excision of the rectum behaved as risk factors for urinary dysfunction. In contrast, Eveno et al. ${ }^{(6)}$ described abdominoperineal resection as one of the main four risk factors for postoperative urinary sequelae, the other three of which were age, preoperative radiation therapy and surgery that fails to respect the "sacred planes" of TME. Moszkowicz et al. ${ }^{(27)}$ suggested that abdominoperineal resection of the rectum is associated with greater functional morbidity due to the need for perineal dissection above and below the levator ani muscle. That manoeuvre would damage not only the pelvic floor muscles, which provide significant support to the pelvic organs, but also the levator ani nerve and the efferent branches of the inferior hypogastric plexus, which include mixed nerves. According to those authors, the damage is due not only to nerve section but also to excessive traction and prolonged electrocoagulation, which are frequent occurrences in patients with either narrow pelvis or anterior rectal wall tumours ${ }^{(27)}$.

The learning curve of laparoscopic colorectal surgery is long, which might hinder the functional outcomes achieved by surgeons at the beginning of their professional training. However, when an experienced surgeon performs the surgery, the laparoscopic approach allows for better visualisation of small structures, such as the pelvic autonomic nerves. Laparoscopy also has advantages over laparotomy due to the image magnification and the 30 -degree angle eyepiece ${ }^{(1,17,23,26,30)}$. The sympathetic component is recognised in more than $90 \%$ of cases and the parasympathetic component in 53\% to $96 \%$; this variation is due to the deeper location of the latter component inside the pelvis ${ }^{(17,30)}$. There is not yet a consensus as to the benefit afforded by video laparoscopy for surgical treatment of rectal cancer regarding the preservation of pelvic organ function. Some studies ${ }^{(16,25,29)}$ compared laparoscopy versus laparotomy and observed functional impairment in the postoperative period, particularly in the sexual area, with impaired male erectile function when video laparoscopy was used. Regarding urinary function, most authors did not find significant impairment among laparoscopic surgeries ${ }^{(4,16,23}$, 26). The results reported by McGlone et al. ${ }^{(23)}$ are significantly favorable to the minimally invasive approach; the authors emphasised the advantages afforded by laparoscopy for the preservation of pelvic function. In a multicentre study ${ }^{(21)}$, 
the results of robotic surgery were comparable to those of laparoscopic surgery or laparotomy, and robotic surgery was associated with low rates of urinary and sexual dysfunction. In the present study, no significant difference was found between the surgical approaches, neither of which behaved as a risk factor for postoperative urinary dysfunction.

\section{CONCLUSIONS}

Urinary dysfuntion can be an outcome and a cause of quality of life impairment among patients underwent to surgical treatment for rectal cancer. This study identified an incidence of $19 \%$ of moderate to severe urinary dysfuction after a 6 months surveillance.

This study was conducted at the Surgical Gastroenterol- ogy Unit of Hospital do Servidor Público Estadual de São Paulo, Instituto de Assistência Médica ao Servidor Público Estadual - IAMSPE, São Paulo (SP), Brazil.

Ethics Comitte and Research: Protocol n ${ }^{\circ}$ 066/11, Instituto de Assistência Médica ao Servidor Público Estadual (IAMSPE), São Paulo, SP, Brazil.

\section{Authors' contributions}

This study was part of Beraldo FB's master's degree therefore he participated in all stages of this manuscript production and publication. Palma RT and Kharmandayan $\mathrm{S}$ assisted the data analysis and Yusuf SAI performed part of manuscript revision and translation. Gonçalves JE e Waisberg $\mathbf{J}$ done the final data analysis and manuscript revision.

Beraldo FB, Yusuf SAI, Palma RT, Kharmandayan S, Gonçalves JE, Waisberg J. Disfunção urinária após tratamento cirúrgico do câncer de reto. Arq Gastroenterol. 2015,52(3):180-5.

RESUMO - Contexto - A perda de qualidade de vida atribuída ao tratamento do câncer retal continua elevada. Neste contexto, a deterioração da função urinária é complicação relevante. Objetivo - Identificar disfunção urinária e seus fatores de risco em doentes submetidos ao tratamento cirúrgico do câncer de reto. Métodos - Realizou-se estudo prospectivo com 42 doentes de ambos os sexos submetidos a tratamento cirúrgico com intenção curativa para adenocarcinoma de reto. Foi utilizado o questionário International Prostatic Symptom Score, validado na língua portuguesa, em dois períodos: imediatamente antes e após 6 meses do procedimento cirúrgico. Os fatores de risco para disfunção urinária foram analisados por regressão logística e teste $t$ de Student. Resultados - Após 6 meses do procedimento cirúrgico, oito (19\%) doentes apresentaram disfunção urinária moderada a grave e aumento na média do escore utilizado de 1,43 pontos no pré-operatório para 4,62 pontos no pós-operatório $(P<0,001)$. A análise de fatores de risco para disfunção urinária não mostrou significância para as variáveis estudadas, idade, gênero, distância tumoral da margem anal, neoadjuvância, adjuvância, procedimento cirúrgico realizado, via de acesso cirúrgico (laparoscópica ou laparotômica) e tempo operatório. Conclusão - Nos doentes com carcinoma retal operados com intenção curativa, a incidência de disfunção urinária moderada a grave após 6 meses da operação foi de 19\%. Não foram identificados fatores de risco para disfunção urinária nesses doentes.

DESCRITORES - Neoplasias retais. Bexiga urinaria neurogênica. Cirurgia colorretal. Terapia neoadjuvante. Plexo hipogástrico. 


\section{REFERENCES}

1. Asoglu O, Matlim T, Karanlik H, Atar M, Muslumanoglu M, Kapran Y, Igci A Ozmen V, Kecer M, Parlak M. Impact of laparoscopic surgery on bladder and sexual function after total mesorectal excision for rectal cancer. Surg Endosc. 2009;23(2):296-303.

2. Barry MJ, Fowler FJ Jr, O'Leary MP, Bruskewitz RC, Holtgrewe HL, Mebust WK, Cockett AT. The American Urological Association symptom index for benign prostatic hyperplasia. The Measurement Committee of the American Urological Association. J Urol. 1992;148(5):1549-57.

3. Berger M, Luz JPN, Silva Neto B, Koff W. Validaçäo estatística do escore internacional de sintomas prostáticos (I-PSS) na língua portuguesa / Statistical validation of the international prostatic symptom score (I-PSS) in Portuguese. J Bras Urol. 1999;25:225-34.

4. Breukink SO, van Driel MF, Pierie JP, Dobbins C, Wiggers T, Meijerink WJ Male sexual function and lower urinary tract symptoms after laparoscopic total mesorectal excision. Int J Colorectal Dis. 2008;23(12):1199-205.

5. Bruheim K, Guren MG, Skovlund E, Hjermstad MJ, Dahl O, Frykholm G Carlsen E, Tveit KM. Late side effects and quality of life after radiotherapy for rectal cancer. Int J Radiat Oncol Biol Phys. 2010;76(4):1005-11.

6. Eveno C, Lamblin A, Mariette C, Pocard M. Sexual and urinary dysfunction after proctectomy for rectal cancer. J Visc Surg. 2010;147(1):e21-30.

7. Fowler CJ, Griffiths D, de Groat WC. The neural control of micturition. Nat Rev Neurosci. 2008;9(6):453-66.

8. Gunderson LL, Sargent DJ, Tepper JE, Wolmark N, O'Connell MJ, Begovic M, et al. Impact of $\mathrm{T}$ and $\mathrm{N}$ stage and treatment on survival and relapse in adjuvant rectal cancer: a pooled analysis. J Clin Oncol. 2004;22(10):1785-96.

9. Habr-Gama A, Perez RO, Sabbaga J, Nadalin W, São Julião GP, Gama-Rodrigues J. Increasing the rates of complete response to neoadjuvant chemoradiotherapy for distal rectal cancer: results of a prospective study using additional chemotherapy during the resting period. Dis Colon Rectum. 2009;52(12):1927-34.

10. Habr-Gama A, Perez RO, Wynn G, Marks J, Kessler H, Gama-Rodrigues J. Complete clinical response after neoadjuvant chemoradiation therapy for distal rectal cancer: characterization of clinical and endoscopic findings for standardization. Dis Colon Rectum. 2010;53(12):1692-8.

11. Heald RJ. The 'Holy Plane' of rectal surgery. J R Soc Med. 1988;81(9):503-8.

12. Heald RJ, Ryall R. Recurrent cancer after restorative resection of the rectum. $\mathrm{Br}$ Med J (Clin Res Ed). 1982;284(6318):826-7.

13. Hendren SK, O'Connor BI, Liu M, Asano T, Cohen Z, Swallow CJ, Macrae HM Gryfe R, McLeod RS. Prevalence of male and female sexual dysfunction is high following surgery for rectal cancer. Ann Surg. 2005;242(2):212-3.

14. Herman JM, Narang AK, Griffith KA, Zalupski MM, Reese JB, Gearhart SL, et al. The quality-of-life effects of neoadjuvant chemoradiation in locally advanced rectal cancer. Int J Radiat Oncol Biol Phys. 2013;85(1):e15-9.

15. How P, Shihab O, Tekkis P, Brown G, Quirke P, Heald R, Moran B. A systematic review of cancer related patient outcomes after anterior resection and abdominoperineal excision for rectal cancer in the total mesorectal excision era. Surg Oncol. 2011;20(4):e149-55.

16. Jayne DG, Brown JM, Thorpe H, Walker J, Quirke P, Guillou PJ. Bladder and sexual function following resection for rectal cancer in a randomized clinical trial of laparoscopic versus open technique. Br J Surg. 2005;92(9):1124-32.
17. Keating JP. Sexual function after rectal excision. ANZ J Surg. 2004;74:248-259.

18. Kosinski L, Habr-Gama A, Ludwig K, Perez R. Shifting concepts in rectal cancer management: a review of contemporary primary rectal cancer treatment strategies. CA Cancer J Clin. 2012;62(3):173-202.

19. Krassioukov A, Biering-Sørensen F, Donovan W, Kennelly M, Kirshblum S, Krogh K, Alexander MS, Vogel L, And Wecht J. International Standards to Document Remaining Autonomic Function after Spinal Cord Injury (ISAFSCI), First Edition 2012. Top Spinal Cord Inj Rehabil. 2012;18(3):282-96.

20. Lange MM, Maas CP, Marijnen CA, Wiggers T, Rutten HJ, Kranenbarg EK, et al. Urinary dysfunction after rectal cancer treatment is mainly caused by surgery. Br J Surg. 2008;95(8):1020-8.

21. Luca F, Valvo M, Ghezzi TL, Zuccaro M, Cenciarelli S, Trovato C, Sonzogni A, Biffi R. Impact of robotic surgery on sexual and urinary functions after fully robotic nerve-sparing total mesorectal excision for rectal cancer. Ann Surg. 2013;257(4):672-8.

22. Maurer CA. Urinary and sexual function after total mesorectal excision. Recent Results Cancer Res. 2005;165:196-204.

23. McGlone ER, Khan O, Flashman K, Khan J, Parvaiz A. Urogenital function following laparoscopic and open rectal cancer resection: a comparative study. Surg Endosc. 2012;26(9):2559-65.

24. Ministério da Saúde, Brasil. Secretaria de Atenção à Saúde. Instituto Nacional de Câncer. TNM: classificação de tumores malignos [Ministry of Health, Brazil. Health Care Secretariat. National Cancer Institute. TNM; classification of malignant tumours] / translated by Ana Lúcia Amaral Eisenberg. 6. ed. Rio de Janeiro: INCA; 2004.

25. Morino M, Allaix ME, Giraudo G, Corno F, Garrone C. Laparoscopic versus open surgery for extraperitoneal rectal cancer: a prospective comparative study. Surg Endosc. 2005;19(11):1460-7.

26. Morino M, Parini U, Allaix ME, Monasterolo G, Brachet Contul R, Garrone C. Male sexual and urinary function after laparoscopic total mesorectal excision. Surg Endosc. 2009;23(6):1233-40.

27. Moszkowicz D, Alsaid B, Bessede T, Penna C, Nordlinger B, Benoît G, Peschaud F Where does pelvic nerve injury occur during rectal surgery for cancer? Colorectal Dis. 2011;13(12):1326-34.

28. Pollack J, Holm T, Cedermark B, Altman D, Holmström B, Glimelius B, Mellgren A. Late adverse effects of short-course preoperative radiotherapy in rectal cancer. Br J Surg. 2006;93(12):1519-25.

29. Quah HM, Jayne DG, Eu KW, Seow-Choen F. Bladder and sexual dysfunction following laparoscopically assisted and conventional open mesorectal resection for cancer. Br J Surg. 2002;89(12):1551-6.

30. Sartori CA, Sartori A, Vigna S, Occhipinti R, Baiocchi GL. Urinary and sexual disorders after laparoscopic TME for rectal cancer in males. J Gastrointest Surg. 2011;15(4):637-43.

31. Sauer R, Becker H, Hohenberger W, Rödel C, Wittekind C, Fietkau R, et al Preoperative versus postoperative chemoradiotherapy for rectal cancer. N Engl J Med. 2004;351(17):1731-40.

32. Wallner C, Lange MM, Bonsing BA, Maas CP, Wallace CN, Dabhoiwala NF, et al. Causes of fecal and urinary incontinence after total mesorectal excision for rectal cancer based on cadaveric surgery: a study from the Cooperative Clinical Investigators of the Dutch total mesorectal excision trial. J Clin Oncol. 2008;26(27):4466-72. 